\title{
Conhecimento de estudantes de medicina sobre o processo de doação de córneas
}

\author{
Theknowledgeof medical students about cornea donation
}

\author{
Rodrigo França de Espíndola ${ }^{1}$ \\ Beatriz Alessi Rodrigues ${ }^{2}$ \\ Lívia Tribst Penteado ${ }^{3}$ \\ Gisela Tan-Ho ${ }^{4}$ \\ José Otávio Alquezar Gozzan 5 \\ João Alberto Holanda de Freitas ${ }^{6}$
}

\section{RESUMO}

Objetivo: Avaliar o conhecimento de estudantes de medicina sobre o processo de doação de córneas, comparando-o entre aqueles que já cursaram a disciplina de Oftalmologia com os demais. Métodos: Foi aplicado um questionário a estudantes de medicina do interior de São Paulo, contendo dados como: idade, sexo, ano de graduação e 10 perguntas de múltipla escolha sobre o tema. As questões abordaram o limite de idade para doação, contra-indicações para o transplante, tempo para retirada das córneas, dentre outras. Foi comparado o conhecimento (\% de acertos) entre aqueles que haviam cursado a disciplina de Oftalmologia (Grupo A) com os demais (Grupo B). Resultados: Foram entrevistados 402 estudantes. Destes, 140 eram do grupo A e 262 do grupo B. Não houve diferença estatisticamente significante entre os dois grupos $(\mathrm{p}=0,8328)$. Conclusão: O conhecimento sobre o processo de doação de córneas mostrou-se insuficiente entre os alunos entrevistados, mesmo para aqueles que haviam cursado a disciplina de Oftalmologia, apontando a necessidade de aperfeiçoamento do conhecimento divulgado nas escolas médicas.

Descritores: Transplante de córnea; Educação em saúde; Questionários; Obtenção de tecidos e órgãos; Estudantes de medicina

\section{INTRODUÇÃO}

A cada ano cresce o número de transplante de córneas (TC) no Brasil. Em 2000, foram realizados 3.505 transplantes. Em 2003, 6.286 ${ }^{(1)}$. Porém, a grande limitação desse tipo de tratamento deve-se à falta de doadores, deixando mais de 22.000 pacientes na lista de espera perdendo apenas para o transplante renal ${ }^{(1)}$.

Mesmo quando ocorre a doação, uma grande parcela das córneas não é efetivada em transplante. No Brasil, no ano de 2002, a contra-indicação médica foi responsável pela não efetivação em 43,5\% dos casos e em 40,1\% não houve autorização familiar ${ }^{(1)}$.

Os dados levantam desafios importantes, como a desinformação da população em relação ao transplante e a contra-indicação médica equivocada. A negativa de consentimento por parte da família poderia ser contornada mais facilmente, se os profissionais envolvidos no processo de captação esclarecessem de forma competente as dúvidas dos familiares. Infelizmente, muitos profissionais não estão preparados para responder a questionamentos sobre a doação ${ }^{(2)}$. Outro fator a ser considerado é a classificação incorreta dos órgãos e tecidos que, por essa razão são rejeitados, diminuindo o número de transplantes.

Portanto, parece ser de grande relevância enfatizar e aprimorar o conhe- 
cimento sobre TC entre acadêmicos de medicina. O objetivo deste estudo foi comparar o nível de conhecimento sobre o processo de doação de córneas entre estudantes de medicina que cursaram a disciplina de Oftalmologia com os demais.

\section{MÉTODOS}

Realizou-se um estudo de delineamento transversal entre 402 estudantes de Medicina do interior de São Paulo, no período de janeiro a março de 2004.

A pesquisa baseou-se na coleta de dados através de questionário padronizado (Anexo) contendo dados como: idade, sexo, ano da graduação e 10 perguntas de múltipla escolha sobre o tema. Foram abordados temas como: limite de idade do doador, tempo máximo para retirada das córneas, condições para doação, contra-indicações e aspectos legais do transplante.

Todos os alunos foram abordados em sala de aula, pouco antes do início de suas atividades, tendo em média 15 minutos para responder de forma espontânea o questionário. Os entre- vistados foram orientados a não mudarem ou rasurarem suas respostas. Questões em branco e/ou rasuradas foram consideradas incorretas.

A disciplina de Oftalmologia na instituição pesquisada é ministrada no quinto ano. Foi comparado o conhecimento (\% de acertos) nos diferentes períodos de graduação e entre aqueles que haviam cursado a disciplina (Grupo A) com os demais (Grupo B).

A amostragem foi por conveniência (não probabilística), envolvendo alunos do primeiro ao sexto ano de graduação. $\mathrm{O}$ número de estudantes analisados foi estabelecido arbitrariamente. Os dados foram analisados descritivamente. Para avaliação estatística foram usados métodos não paramétricos (teste qui-quadrado). $\mathrm{O}$ valor de $\mathrm{p}$ foi determinado em cada teste.

\section{RESULTADOS}

Foram entrevistados 402 estudantes, $255(63,4 \%)$ eram do sexo feminino, com idade média de 22 anos (17-34 anos). A

\section{Anexo - Questionário. Conhecimentos dos estudantes de medicina sobre o processo de doação de órgãos}

\section{Identificação:}

Ano de graduação:

\section{Questionário:}

1- Qual o limite de idade para ser doador de córneas?
( ) 20 anos
( ) 40 anos
( ) 60 anos
( ) não há limite

2- Qual é o tempo máximo em que as córneas podem ser retiradas de um doador?
( ) $1 \mathrm{~h}$
( ) $2 \mathrm{~h}$
( ) $6 \mathrm{~h}$
( ) $24 \mathrm{~h}$
( ) não há tempo máximo

3- Portador de deficiência visual (ex: miopia, hipermetropia, astigmatismo) pode ser doador?
( ) $\operatorname{sim}$
( ) não

4- Em que condições as córneas podem ser retiradas para doação?

( ) em doador vivo

( ) quando o doador estiver em estado de coma

( ) podem ser retiradas em caso de parada cardio-respiratória

( ) somente em caso de morte encefálica

5- Quando um doador morre, quais os cuidados necessários para se manter as córneas adequadas para o transplante?

( ) deve-se manter as pálpebras fechadas

( ) deve-se manter as pálpebras abertas e cobertas com gaze embebida em soro fisiológico

( ) não há necessidade de cuidados especiais com as córneas

6- Há deformação perceptível do cadáver, após a retirada das córneas?
( ) $\operatorname{sim}$
( ) não

7- Qual destas doenças contra-indica a doação de córneas?
( ) infarto do miocárdio
( ) diabetes mellitus
( ) hipertensão arterial
( ) doenças infecciosas
( ) nenhuma doença impossibilita a doação

8- Há necessidade da cor dos olhos do doador ser a mesma do receptor?
( ) $\operatorname{sim}$
( ) não, mas devem ter tonalidades semelhantes
( ) não

9- Como faço para ser doador de córneas?

( ) informar minha família do meu desejo, pois a autorização depende dela

( ) autorização por escrito do doador, em documento registrado em cartório ou na carteira de motorista

( ) não é necessário autorização, pois a retirada é imperceptível pela família

10- Posso ser doador exclusivamente de córneas, e não de outros órgãos e tecidos?

( ) $\operatorname{sim}$

( ) não, pois quando se é doador retira-se todos tecidos e órgãos viáveis para transplante 
distribuição dos alunos por ano de graduação encontra-se demonstrada no gráfico 1 .

Em relação aos alunos que haviam cursado a disciplina de Oftalmologia (Grupo A), a média de acertos foi de $59,5 \%$. Dentre os demais (Grupo B) de 55,5\%, conforme gráfico 3. Não houve diferença estatisticamente significante entre os dois grupos $(\mathrm{p}=0,8328)$.

O percentual de acerto de cada questão está demonstrado no gráfico 2 .

A tabela 1 apresenta a comparação do conhecimento entre os Grupos A e B. Foi identificada diferença estatisticamente significante em 4 questões. Em relação ao tempo de retirada das córneas $(\mathrm{p}<0,0000)$ e da necessidade da mesma cor dos olhos para ser doador ( $\mathrm{p}<0,0010$ ), o Grupo que cursou Oftalmologia (A), apresentou maior índice de acertos. As questões que abordavam o limite de idade para ser um doador $(\mathrm{p}<0,0000)$ e a possibilidade de doar apenas as córneas para o transplante $(\mathrm{p}<0,0000)$ apresentaram predomínio de acertos no Grupo B (não cursaram Oftalmologia).

\section{DISCUSSÃO}

O conhecimento da equipe médica é fundamental para possibilitar um aumento do número de captações e, conseqüentemente, da quantidade de TC realizados. Já ficou demonstrado que, quando a entrevista para obtenção do consentimento para doação era conduzida por um médico experiente, gerava uma média de doações de $80,3 \%$. Se realizada por médicos inexperientes as doações reduziam para $35,5 \%{ }^{(2)}$.

Outro estudo apontou que somente $5,0 \%$ dos médicos possuem domínio completo das indicações e contra-indicações sobre o transplante. Destes $27,0 \%$ erraram quanto às contra-indicações para o $\mathrm{TC}^{(3)}$. Outras pesquisas também identificaram o despreparo dos profissionais durante o processo de captação de órgãos, tanto nos seus conhecimentos médicos como na técnica de abordagem dos familiares ${ }^{(4-5)}$.

A média geral de acertos das questões entre os alunos que já haviam cursado Oftalmologia (Grupo A) e os demais (Grupo B) não apresentou diferença estatística $(\mathrm{p}=0,8328)$.

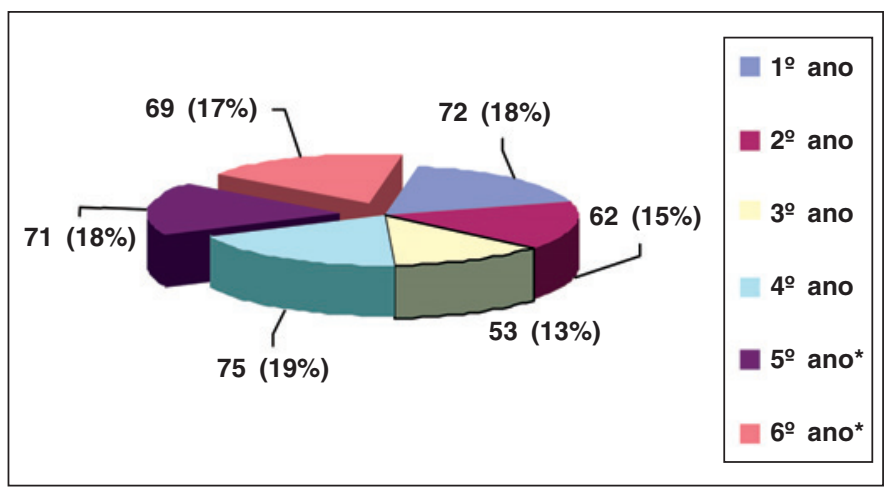

Gráfico 1 - Distribuição dos estudantes por ano de graduação. *Grupo A - Cursaram Oftalmologia.
No entanto, quando estudamos as questões separadamente, encontramos diferenças significativas entre elas. Assim, o Grupo B apresentou um maior índice de acertos, com significado estatístico em duas questões: limite de idade do doador e possibilidade de doar apenas as córneas. O Grupo A apresentou maior índice de acertos, com significado estatístico em duas outras questões: tempo máximo de retirada das córneas e necessidade da mesma cor dos olhos para ser doador.

As questões que os estudantes do Grupo A apresentaram maior percentual de acerto estavam relacionadas diretamente ao conteúdo da disciplina, enquanto que as questões com melhor desempenho entre os demais alunos (Grupo B) eram de caráter mais geral, podendo ser adquirido em outro momento do curso.

O Estado de São Paulo é responsável pela maioria dos TC de córneas realizados no Brasil. Cerca de 50,0\% destes transplantes são realizados no interior do Estado ${ }^{(6)}$. Portanto, era de se esperar que mesmo alunos do primeiro ao quarto ano, que não tiveram contato com a disciplina, apresentassem melhor desempenho, seja adquirido por campanhas, periódicos, internet, ou por outras fontes.

A baixa média de acertos das questões propostas aos estudantes aponta uma deficiência de conhecimento sobre o processo de doação, levando à necessidade de aperfeiçoar as

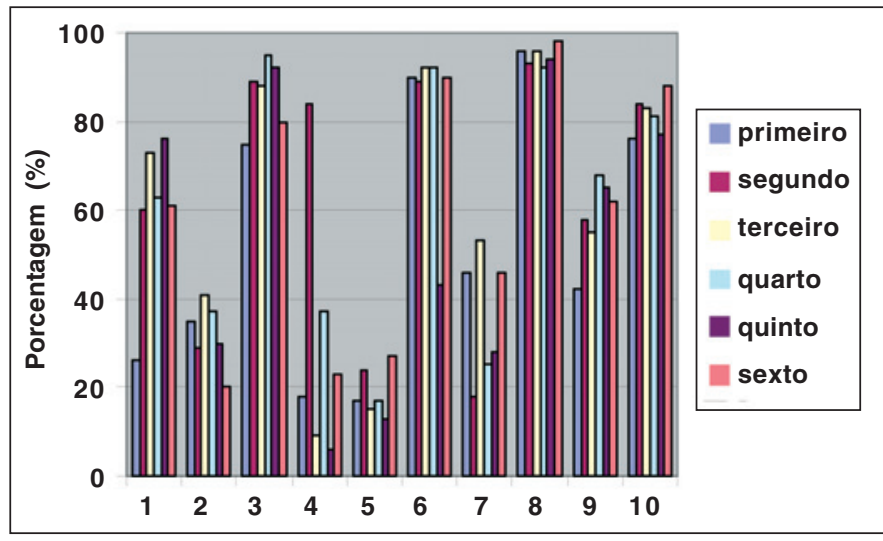

Gráfico 2 - Análise das questões (porcentagem de acerto) entre acadêmicos do primeiro ao sexto ano de medicina

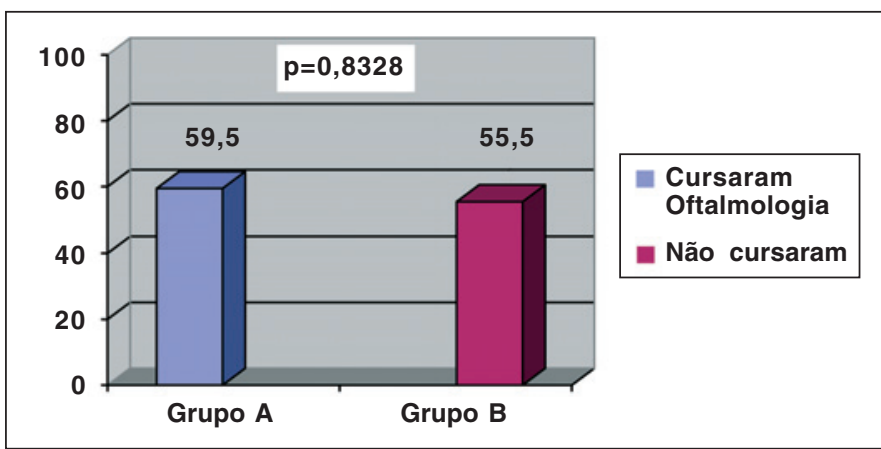

Gráfico 3 - Porcentual de acertos entre alunos que cursaram Oftalmologia e os que não cursaram 


\begin{tabular}{|c|c|c|c|}
\hline & Grupo A (\%) & Grupo B (\%) & Valor de $p$ \\
\hline Limite de idade do doador & 67,4 & $91,2^{\star \star}$ & 0,0000 \\
\hline Tempo máximo de retirada das córneas & $79,4^{*}$ & 55,2 & 0,0000 \\
\hline Portadores de deficiências visuais podem doar & 88,7 & 86,6 & 0,5532 \\
\hline Condições para a retirada das córneas & 20,6 & 17,6 & 0,4698 \\
\hline Cuidados com as córneas & 83,7 & 79,7 & 0,3290 \\
\hline Necessidade da mesma cor dos olhos & $70,9^{*}$ & 54,0 & 0,0010 \\
\hline Autorização familiar para a doação & 38,3 & 33,7 & 0,3591 \\
\hline Possibilidade de doar apenas as córneas & 17,0 & $37,5^{\star \star}$ & 0,0000 \\
\hline
\end{tabular}

informações sobre o assunto nas escolas médicas. Esse tema se torna importante, pois estes alunos em breve serão o profissional que abordará os familiares de potenciais doadores, ou seja, peças fundamentais para o aumento do número de captações e transplantes de córnea.

\section{CONCLUSÃO}

Este estudo entre estudantes de Medicina do interior de São Paulo, demonstrou a falta de conhecimentos sobre o processo de doação de córneas, mesmo para aqueles que haviam cursado a disciplina. Este fato levanta a necessidade de um aperfeiçoamento do conhecimento divulgado nas escolas médicas como forma de conscientização e de aumento do número de doações e transplantes.

\section{ABSTRACT}

Purpose: To compare knowledge of medical students about the cornea donation process among those who already studied Ophthalmology and the others. Methods: A questionnaire containing data as: age, sex, graduation year, and 10 multiple-choice questions about the subject was applied to medical students from the interior of São Paulo state, Brazil. The questions were: age for donation, contraindication for transplants, the time limit to remove the cornea, among others. The knowledge regarding cornea donation was compared between the two groups: students who already studied Oph- thalmology (Group A) and the others (Group B). Results: The study group was composed of 402 students, of whom 140 were of group A and 262 of group B. Knowledge between the two groups was different, but not statistically significant $(p=0.8328)$. Conclusion: Knowledge about the cornea donation process among the interviewed seemed to be insufficient, even those who had studied Ophthalmology. Information and education about transplants in Medical Schools should be improved.

Keywords: Cornea transplantation; Health education; Questionnaire; Tissue and organ procurement; Students, medical

\section{REFERÊNCIAS}

1. Associação Brasileira de Transplantes de Órgãos. [sitio na Internet]. São Paulo: ABTO. [citado 2006 Nov 21]. Disponível em: http://www.abto.org.br

2. Muraine M, Menguy E, Martin J, Sabatier P, Watt L, Brasseur G. The interview with the donor's family before post mortem procurement. Cornea. 2000;19(1):12-6.

3. Ploeg RJ, Niesing J, Sieber-Rash MH, Willems L, Kranenburg K, Geertsma A. Shortage for donation despite an adequate number of donors: A professional attitude? Transplantation. 2003;76(6):948-55.

4. Alves MR, Crestana FP, Kanatami R, Cresta FB, José NK. Doação de córneas: opinião e conhecimento de médicos intensivistas do Complexo Hospital das Clínicas da Faculdade de Medicina da Universidade de São Paulo. Revista Méd (São Paulo). 1997;76(6):315-9.

5. Rodrigues AM, Sato E. Entendimento dos médicos intensivistas sobre o processo de doação de córneas. Arq Bras Oftalmol. 2003;66(1):29-32.

6. Brasil. Ministério da Saúde. Sistema Nacional de Transplantes. [sitio na Internet]. Brasília: STN. [citado 2006 Out 15]. Disponível em: http://www. saude.gov.br/transplantes 